\title{
A mixed methods analysis of environmental and household chaos: considerations for early-childhood obesity research
}

Kathryn L. Krupsky ${ }^{1 *}$, Andria Parrott ${ }^{2}$, Rebecca Andridge ${ }^{3}$, Bharathi J. Zvara ${ }^{4}$, Sarah A. Keim ${ }^{1,2,5}$ and Sarah E. Anderson ${ }^{1}$

\begin{abstract}
Background: Chaos has implications for child health that may extend to childhood obesity. Yet, results from studies describing associations between chaos and childhood obesity are mixed. New approaches to studying the environments of young children may help to clarify chaos-obesity relationships.

Methods: We conducted a concurrent mixed methods analysis of quantitative and qualitative data describing home and neighborhood chaos among a diverse cohort of 283 caregiver-toddlers dyads from Ohio. We examined the underlying structure of environmental and household chaos using exploratory factor analysis then sought to validate the structure using qualitative field notes. We generated total scores for factors of chaos and described their distributions overall and according to cohort characteristics. Additionally, we conducted a thematic content analysis of brief ethnographies to provide preliminary construct validity for our indicators of chaos.

Results: Dyads varied according to household composition, income, education, and race/ethnicity. We found evidence for a multi-factor structure for chaos, which included disorganization and neighborhood noise. Household disorganization scores ranged from 0 to 7.3 and were on average 2.1 (SD =1.8). Neighborhood noise scores ranged from 0 to 4 and were on average $1.1(S D=1.1)$. Both disorganization and neighborhood noise were associated with indicators of socioeconomic disadvantage, such as lower educational attainment and household income.

Qualitative data from households with high and low scores on the two identified factors were aligned in ways that were supportive of construct validity and further contextualized the social and material environments in which chaos occurred.
\end{abstract}

\footnotetext{
* Correspondence: krupsky.1@osu.edu

'Division of Epidemiology, College of Public Health, The Ohio State University, 336 Cunz Hall, 1841 Neil Ave, Columbus, OH 43210, USA

Full list of author information is available at the end of the article
}

(c) The Author(s). 2021 Open Access This article is licensed under a Creative Commons Attribution 4.0 International License, which permits use, sharing, adaptation, distribution and reproduction in any medium or format, as long as you give appropriate credit to the original author(s) and the source, provide a link to the Creative Commons licence, and indicate if changes were made. The images or other third party material in this article are included in the article's Creative Commons licence, unless indicated otherwise in a credit line to the material. If material is not included in the article's Creative Commons licence and your intended use is not permitted by statutory regulation or exceeds the permitted use, you will need to obtain permission directly from the copyright holder. To view a copy of this licence, visit http://creativecommons.org/licenses/by/4.0/ The Creative Commons Public Domain Dedication waiver (http://creativecommons.org/publicdomain/zero/1.0/) applies to the data made available in this article, unless otherwise stated in a credit line to the data. 
Conclusions: Chaos represents a complex construct with implications spanning various disciplines, including childhood obesity research. Previous studies suggest challenges associated with measuring chaos may limit the conclusions that can be drawn about which aspect of chaos (if any) matter most of early childhood weight development. We advance the literature by demonstrating chaos may be comprised of conceptually distinct subdomains. Future childhood obesity prevention research may benefit from more contemporary measure of chaos, such as those relying on direct observations that account for a multifaceted underlying structure.

Keywords: Toddlers, Childhood obesity, Chaos, Mixed methods, Prevention

\section{Background}

\section{Childhood obesity}

Childhood obesity remains prevalent across the world, presenting one of the most challenging public health problems of this century [1]. Once established, obesity and related comorbid chronic conditions often persist into adolescence and adulthood [2]. The persistent nature of this condition may result from the establishment of obesity-related behaviors in early childhood, including poor diet, obesogenic eating behaviors, and physical inactivity, which often track through adulthood [3]. Therefore, infancy and toddlerhood (birth to 24-months) may be critical periods for obesity prevention efforts.

Health behavior patterns underlying the development of childhood obesity are influenced by a complex ecology of factors [4]. Thus, interventions designed to change obesity-related behaviors require multilevel approaches with multiple components [5]. Currently, no compelling evidence advocates for one program or method for preventing childhood obesity. However, comprehensive approaches addressing both behavioral risk factors and psychosocial support within relevant contexts tend to offer more promising outcomes [6, 7]. For young children, family homes are ideal settings for the implementation of childhood obesity preventions strategies [8-11], as the family home represents a microsystem of processes by which child functioning is shaped [12]. However, more research is needed to understand how features of family homes may influence such efforts.

\section{Chaos and childhood obesity}

Chaos is one feature of family home environments that may be consequential for early-childhood weight development, but evidence is mixed. For example, crosssectional studies investigating direct associations between chaos and weight status among preschool-aged children report null findings $[13,14]$. One prospective study of caregiver-reported chaos, measured twice over a six-month period, indicated higher levels of chaos were associated with higher body mass index (BMI) z-score in among infants [15]. Other studies propose chaos may operate through mediators such as cortisol patterns, child eating behaviors, and sleep duration to contribute to poorer child weight outcomes $[14,16]$.
Chaotic environments are often described as noisy, crowded, and lacking organization [17]. Furthermore, both structural and temporal instability in the form of frequent changes in adults' romantic partners, residential mobility, loss of family income, and disrupted family routines and rituals may also contribute to chaos [18]. Chaos is more likely to occur among households with fewer socioeconomic resources [17]. However, transdisciplinary research consistently demonstrates the detrimental effects of chaos on child health and development, above and beyond the influence of socioeconomic status (SES) [17-19], even among samples that are homogeneous, with regards to SES [20]. Moreover, it has been proposed that chaos may act as the mechanism by which SES affects child health and development [20-22].

Within the context of the family home, chaos may undermine essential processes that facilitate healthy weight development [23]. For example, the elevated stimulation and unpredictability associated with higher levels of chaos may be stressful for young children [14]. Additionally, caregivers living in more chaotic households may exhibit less warmth and responsiveness towards their children [24, 25]. It has been proposed that the ways in which caregivers respond to their children during moments of heightened stress may impact the organization of emerging stress physiology in early life [26]. The mechanisms responsible for physiological responses to stress are closely related to the processes governing mood and appetite regulation $[27,28]$, which are linked to obesogenic child eating behaviors [29, 30]. Moreover, caring for a small child is difficult and can be stressful for caregivers, especially as children reach toddlerhood and demand more autonomy [31]. The rapid development occurring in toddlerhood is often coupled with new behaviors that may add to familylevel chaos and create barriers to establishing household structure and routines, which may protect against obesity in early childhood [32]. Thus, examining chaos amidst the unique challenges of toddlerhood may provide critical information that can be used to inform early childhood obesity prevention strategies. 


\section{Measuring Chaos in childhood obesity research}

A recent systematic review of chaos and structure in family home environments in relation to early childhood obesity found associations with child weight outcomes in the majority (10 of 14) of studies, but the direction of results was inconsistent, and measures of chaos differed substantially [33]. This variability is likely due, in part, to challenges associated with measuring chaos. Chaos is complex and is thought to be composed of multiple constructs [34], yet most studies examining chaos-obesity relationships refer to only specific indicators of chaos, like crowding [35] or a lack of routines [32, 36]. Conversely, other popular measures, such as the Confusion, Hubbub, and Order Scale (CHAOS) [37], may lack the nuance necessary to identify important subdomains of chaos [34]. Coinciding with this critique, Lumeng and colleagues (2014) used a subset of eight items to describe "emotional chaos" as a component of the CHAOS measure, in their study of stress, eating behaviors, and early-childhood weight outcomes [14]. Furthermore, measures like the CHAOS rely on caregiver perceptions which tend to be subjective and influenced by factors such as coping strategies and personality traits [38].

One potentially promising strategy for measuring family-level chaos may include direct observations of family homes using numerous environmental indicators. To the best of our knowledge, no study has described such a strategy in the childhood obesity literature. However, examples exist in other research domains. For instance, lead investigators of The Family Life Project [39], a study designed to longitudinally assess child health and development and family function among households living in low-income rural regions of the U.S. [39], conducted five direct observations of household chaos over a three year period using 10 indicators (e.g., household moves and household cleanliness) [34]. Factor analyses of these 10 indicators resulted in a two factor structure consisting of disorganization and instability [34]. In subsequent analyses of these chaos findings from the Family Life Project, researchers showed that chaos in the form of disorganization was more important for outcomes like child language development [34] and academic achievement [22], than chaos in the form of instability. Thus, a more objective approach to assessing chaos using multiple chaos-related conditions may support efforts to reconceptualize aspects of chaos and determine which (if any) matter for early-childhood weight outcomes.

\section{Study aims and objectives}

In the present study, we aimed to characterize the home and neighborhood environments of a contemporary cohort of toddlers and explore potential contributors to chaotic environments. Our analyses utilized direct observations of family homes. To accomplish our aim, we examined chaos using a concurrent mixed methods research design. The objectives for this study were (1) to examine the underlying structure of environmental and household chaos using direct observations of the immediate neighborhood and family home environment and (2) to establish preliminary evidence for construct validity using qualitative fieldnotes. We hypothesized that more comprehensive and nuanced assessments of family home environments would provide additional evidence for a multi-factor structure of chaos, including disorganization, noise, and instability. We then discussed our findings in the context of current early childhood obesity literature and offer considerations for future studies.

\section{Methods \\ Study population}

Data are from Play \& Grow-a prospective cohort study of 299 parent-child dyads from central Ohio. Study design and cohort characteristics for the Play \& Grow Study have been previously described [40] but are briefly summarized here. The target population for Play \& Grow included 18-month-old children ( \pm 2 months) living in central Ohio. A sampling frame was constructed using patient medical records from Nationwide Children's Hospital $(\mathrm{NCH})$ in Columbus, Ohio. Caregiverchild dyads were enrolled between 2017 and 2019. Dyads enrolled included primary caregivers $(93 \%$ biological mothers) and children who were born singleton with gestational ages between 23 and 42 weeks. Enrolled dyads lived within 15 miles of $\mathrm{NCH}$ with no family plans to move beyond that radius during the study and the participating caregiver attested to taking part in the child's meals on a regular basis. Participants were excluded from recruitment if the child had deafness, blindness, food allergies, gestational age $>42$ weeks, or if the child was tube-fed or a patient for a clinical feeding disorder. The final cohort consisted of caregiver-child dyads who were diverse with regards to gestational age, race/ethnicity, household composition, education, and household income (Table 1).

Play \& Grow is ongoing. Thus, we utilized data from the first and second assessments, which took place when children were approximately 18- and 24-months of age. Assessments included caregiver surveys and direct observations of family homes. We limited or analyses to only records with complete data on the variables examined in this study $(n=283)$. Our analytic sample differed from the original Play \& Grow cohort, with regards to caregiver age, food insecurity, and household income (Table 1). The study was conducted in accordance with the Declaration of Helsinki and the Institutional Review Board of $\mathrm{NCH}$ approved study procedures. Researchers 
Table 1 The distribution of participant characteristics from the full Play \& Grow cohort compared to participant characteristics of our analytic sample

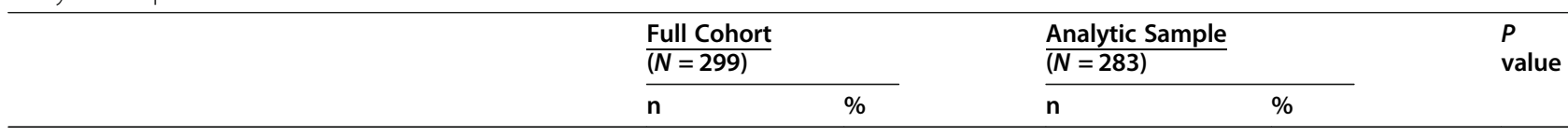

\section{Child Characteristics}

Gestational Age at Birth

37-41 Completed Weeks (term)

$<37$ Completed Weeks (preterm)

Sex

Boy

Girl

Primary Respondent Characteristics

Age (years) at enrollment

$$
\begin{aligned}
& 18 \text { to }<21 \\
& 21 \text { to }<25 \\
& 25 \text { to }<30 \\
& 30 \text { to }<35 \\
& 35 \text { to }<40 \\
& 40 \text { or older }
\end{aligned}
$$

Race/Ethnicity

$$
\text { Non-Hispanic white }
$$$$
\text { Non-Hispanic Black }
$$$$
\text { Non-Hispanic other (includes multiple races) }
$$$$
\text { Hispanic }
$$

Educational Attainment

High school diploma/GED or less

Some college

Bachelor's degree

Post-graduate degree

Marital Status

Single/Never Married

Married

Living with Partner

Other

\section{Household Characteristics}

Number of Household Members

2 members

3 members

4 members

5 or more members

Food Insecurity

Food Secure

Food Insecure

Annual Household Income

$<\$ 20$ thousand

$\$ 20$ to $<\$ 50$ thousand
62.9

37.1

56.9

43.1
0.10

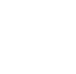

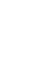


Table 1 The distribution of participant characteristics from the full Play \& Grow cohort compared to participant characteristics of our analytic sample (Continued)

\begin{tabular}{|c|c|c|c|c|c|}
\hline & \multicolumn{2}{|c|}{$\frac{\text { Full Cohort }}{(N=299)}$} & \multicolumn{2}{|c|}{$\frac{\text { Analytic Sample }}{(N=283)}$} & \multirow[t]{2}{*}{$\begin{array}{l}P \\
\text { value }\end{array}$} \\
\hline & $\mathrm{n}$ & $\%$ & $n$ & $\%$ & \\
\hline$\$ 50$ to $<\$ 90$ thousand & 57 & 19.1 & 57 & 20.1 & \\
\hline$\$ 90$ thousand or more & 73 & 24.4 & 73 & 25.8 & \\
\hline Missing & 2 & 0.7 & 2 & 0.7 & \\
\hline
\end{tabular}

Note: Cohort characteristics were predominately reported by caregivers via survey during the 18-month (enrollment) visit for Play \& Grow. $P$ values were generated from Chi-square tests. Food insecurity was assessed using the U.S. Department of Agriculture Food and Nutrition Service's guidelines for measuring food security. We coded families as having food insecurity if they indicated experiencing any level food insecurity in the 12-months prior to them completing our surveys

obtained written documentation of informed consent for all subjects.

\section{Data collection}

We utilized Rapid Assessment Procedures (RAP) [41] to simultaneously collect quantitative and qualitative data describing neighborhood and household conditions. RAP make use of traditional anthropological techniques, such as participant observation, interviewing, and analysis of quantitative data, over a shortened and more focused period of fieldwork [41]. Typically, RAP are implemented by multidisciplinary teams across multiple sites, include prompt turn arounds on data analyses, and are participatory in nature $[41,42]$. While RAP may never meet the methodological standards sought by most anthropologists, researchers across disciplines increasingly recognize the advantages of RAP for gaining insight into complex social and material settings. For example, RAP have been used in domains including health education [43], pandemic response in clinical settings [44], and health information technologies [45]. Our RAP consisted of quantitative audits of neighborhood and household characteristics and participant observation techniques in neighborhoods and family homes.

\section{Observations of neighborhood and household environments}

As part of the second wave of data collection, pairs of trained researchers drove to participant homes when children were 24-months of age. Teams consisted of a Lead and an Assistant Researcher. The Lead Researcher directed the visit and led a variety of study protocols. The Assistant Researcher provided support and was tasked with conducting an extensive mixed methods observation of neighborhood and household conditions. To facilitate this observation, we designed a novel data collection tool to describe a variety of neighborhood and household conditions by adapting existing environmental audits and questionnaires [34, 37, 46-48] (Table 2).

The Assistant Researcher was also trained to supplement quantitative observation data with a rapid participant observation to describe various conditions and interactions noted in participants' neighborhoods and homes. Participant observation is a traditional anthropological technique often used when researchers aim to develop an understanding of participants' lived experiences amidst natural settings [52]. We adapted key features of participant observation to be implemented over numerous home visits lasting approximately 100 minutes each.

For at least $10 \mathrm{~min}$ prior to the start of the home visit, the immediate neighborhood (the spaces visible from the participant's home) was observed from the vehicle with the windows down (weather permitting). The Assistant Researcher also examined the exterior of the family home while unpacking study materials from the vehicle and walking to the entrance of the participant's home. The interior of family homes was observed for the remainder of the scheduled visit (approximately $90 \mathrm{~min}$ ). The Assistant Researcher was permitted to interact with participants in ways that built rapport. However, conversations between the study team and participants occurred mostly with the Lead Researcher. This left ample time for the Assistant to observe and discreetly write descriptive fieldnotes. Assistant Researchers were also encouraged to practice critical self-reflexivity by writing notes describing their experiences, challenges, or personal biases they noticed while conducting observations. Following visits, study staff returned to research offices where they logged their neighborhood and household observations and wrote a brief ethnography using their jotted fieldnotes.

\section{Research staff training and reliability}

Prior to data collection, research staff received a half-day training involving a two-hour classroom session (discussing skills and techniques of ethnography [53]) and a two-hour field practice component. A second classroom-based review session was conducted once data collection was underway. Photos of varying neighborhood and household conditions were rated and discussed. Detailed descriptions of each rating were 
Table 2 Description of items considered as indicators of neighborhood and household chaos

\begin{tabular}{|c|c|c|c|c|c|}
\hline Item & Indicator & $\begin{array}{l}\text { Original Question } \\
\text { Stem }\end{array}$ & $\begin{array}{l}\text { Original } \\
\text { Response } \\
\text { Format }\end{array}$ & $\begin{array}{l}\text { Modified Question } \\
\text { Stem }\end{array}$ & $\begin{array}{l}\text { Modified } \\
\text { Response } \\
\text { Format }\end{array}$ \\
\hline 1 & $\begin{array}{l}\text { Interior Noise } \\
\text { Rating [34] }\end{array}$ & $\begin{array}{l}\text { House is not overly noisy (e.g., TV, shouts of } \\
\text { children, radio, nearby roads or thoroughfares) }\end{array}$ & $\begin{array}{l}\text { No; } \\
\text { Yes }\end{array}$ & $\begin{array}{l}\text { How would you rate the amount of noise inside } \\
\text { the home? Focus on the noise produced by } \\
\text { appliances, people, animals, etc. inside the home }\end{array}$ & $\begin{array}{l}\text { Very quiet; } \\
\text { Fairly quiet; } \\
\text { Somewhat } \\
\text { noisy; } \\
\text { Very noisy }\end{array}$ \\
\hline 2 & $\begin{array}{l}\text { Hear Exterior } \\
\text { Noise Inside } \\
\text { [34] }\end{array}$ & Neighborhood noise around the home & $\begin{array}{l}\text { Cannot } \\
\text { rate; } \\
\text { Very quiet; } \\
\text { Average; } \\
\text { Noisy; } \\
\text { Very noisy }\end{array}$ & $\begin{array}{l}\text { Is noise from outside the home audible when } \\
\text { standing inside the home? Is there presence of } \\
\text { loud ambient sounds (e.g., trains, construction, } \\
\text { factories, traffic, people outside)? }\end{array}$ & $\begin{array}{l}\text { No; } \\
\text { Yes }\end{array}$ \\
\hline 3 & $\begin{array}{l}\text { Rating of } \\
\text { Exterior Noise } \\
\text { Audible Inside } \\
\text { [34] }\end{array}$ & Neighborhood noise around the home & $\begin{array}{l}\text { Cannot } \\
\text { rate; } \\
\text { Very quiet; } \\
\text { Average; } \\
\text { Noisy; } \\
\text { Very noisy }\end{array}$ & $\begin{array}{l}\text { How would you rate the amount of outside } \\
\text { noise audible from inside the home? }\end{array}$ & $\begin{array}{l}\text { Very quiet; } \\
\text { Fairly quiet; } \\
\text { Somewhat } \\
\text { noisy; } \\
\text { Very noisy }\end{array}$ \\
\hline 4 & $\begin{array}{l}\text { Noise } \\
\text { Pollution [46] }\end{array}$ & Noise Pollution & $\begin{array}{l}\text { None; } \\
\text { A little; } \\
\text { Some; } \\
\text { A lot }\end{array}$ & $\begin{array}{l}\text { Is there presence of loud ambient sounds? Can } \\
\text { you hear trains, construction, factories, loud } \\
\text { engines, etc.? }\end{array}$ & $\begin{array}{l}\text { No; } \\
\text { Yes }\end{array}$ \\
\hline 5 & $\begin{array}{l}\text { Exterior Noise } \\
\text { Rating [49] }\end{array}$ & Amount of Noise & $\begin{array}{l}\text { Very quiet; } \\
\text { Fairly quiet; } \\
\text { Somewhat } \\
\text { noisy; } \\
\text { Very noisy }\end{array}$ & How would you rate the level of noise overall? & $\begin{array}{l}\text { Very quiet; } \\
\text { Fairly quiet; } \\
\text { Somewhat } \\
\text { noisy; } \\
\text { Very noisy }\end{array}$ \\
\hline $6^{*}$ & $\begin{array}{l}\text { Number of } \\
\text { Changes to } \\
\text { Household } \\
\text { Roster }\end{array}$ & $\begin{array}{l}\text { Sum of total changes (e.g., people leaving or } \\
\text { joining household) to household roster } \\
\text { between 18- and 24-month assessment }\end{array}$ & & & $\begin{array}{l}\text { No } \\
\text { changes; } \\
1 \text { change; } \\
2 \text { or more } \\
\text { changes }\end{array}$ \\
\hline $7^{*}$ & $\begin{array}{l}\text { Regular } \\
\text { Mealtime } \\
\text { Routine [50] }\end{array}$ & Mealtimes occur at the same time each day & & & $\begin{array}{l}\text { Strongly } \\
\text { disagree; } \\
\text { Disagree; } \\
\text { Neither } \\
\text { agree nor } \\
\text { disagree; } \\
\text { Agree; } \\
\text { Strongly } \\
\text { agree }\end{array}$ \\
\hline $8^{*}$ & $\begin{array}{l}\text { Number of } \\
\text { Adults in the } \\
\text { Household }\end{array}$ & $\begin{array}{l}\text { Sum of the total number of adults (age } \geq 18 \\
\text { years) in household at 24-month visit }\end{array}$ & & & $\begin{array}{l}1 \text { adult; } \\
2 \text { adults; } \\
3 \text { adults; } \\
4 \text { or more } \\
\text { adults }\end{array}$ \\
\hline $9^{*}$ & $\begin{array}{l}\text { Number of } \\
\text { Children in } \\
\text { the Household }\end{array}$ & $\begin{array}{l}\text { Sum of the total number of children (age }<18 \\
\text { years) in household at 24-month visit }\end{array}$ & & & $\begin{array}{l}1 \text { child; } \\
2 \text { children; } \\
3 \text { children; } \\
4 \text { or more } \\
\text { children }\end{array}$ \\
\hline $10^{*}$ & $\begin{array}{l}\text { Caregiver } \\
\text { Marital Status } \\
\text { Change }\end{array}$ & $\begin{array}{l}\text { During our last visit, you told us that your } \\
\text { marital status was: [MARITAL STATUS]. Is this } \\
\text { your current marital status or has your marital } \\
\text { status changed? }\end{array}$ & & & $\begin{array}{l}\text { Did not } \\
\text { change; } \\
\text { Did } \\
\text { changed }\end{array}$ \\
\hline $11^{*}$ & $\begin{array}{l}\text { Total } \\
\text { Residential } \\
\text { Moves }\end{array}$ & $\begin{array}{l}\text { How many times have you moved since } \\
\text { [CHILD] was born? }\end{array}$ & $\begin{array}{l}\text { Did not } \\
\text { move; } \\
\text { Once; } \\
\text { Twice; } \\
3 \text { times } \\
4 \text { time; } \\
\text { More than }\end{array}$ & & $\begin{array}{l}0 \text { times; } \\
1 \text { time; } \\
2 \text { or more } \\
\text { times }\end{array}$ \\
\hline
\end{tabular}


Table 2 Description of items considered as indicators of neighborhood and household chaos (Continued)

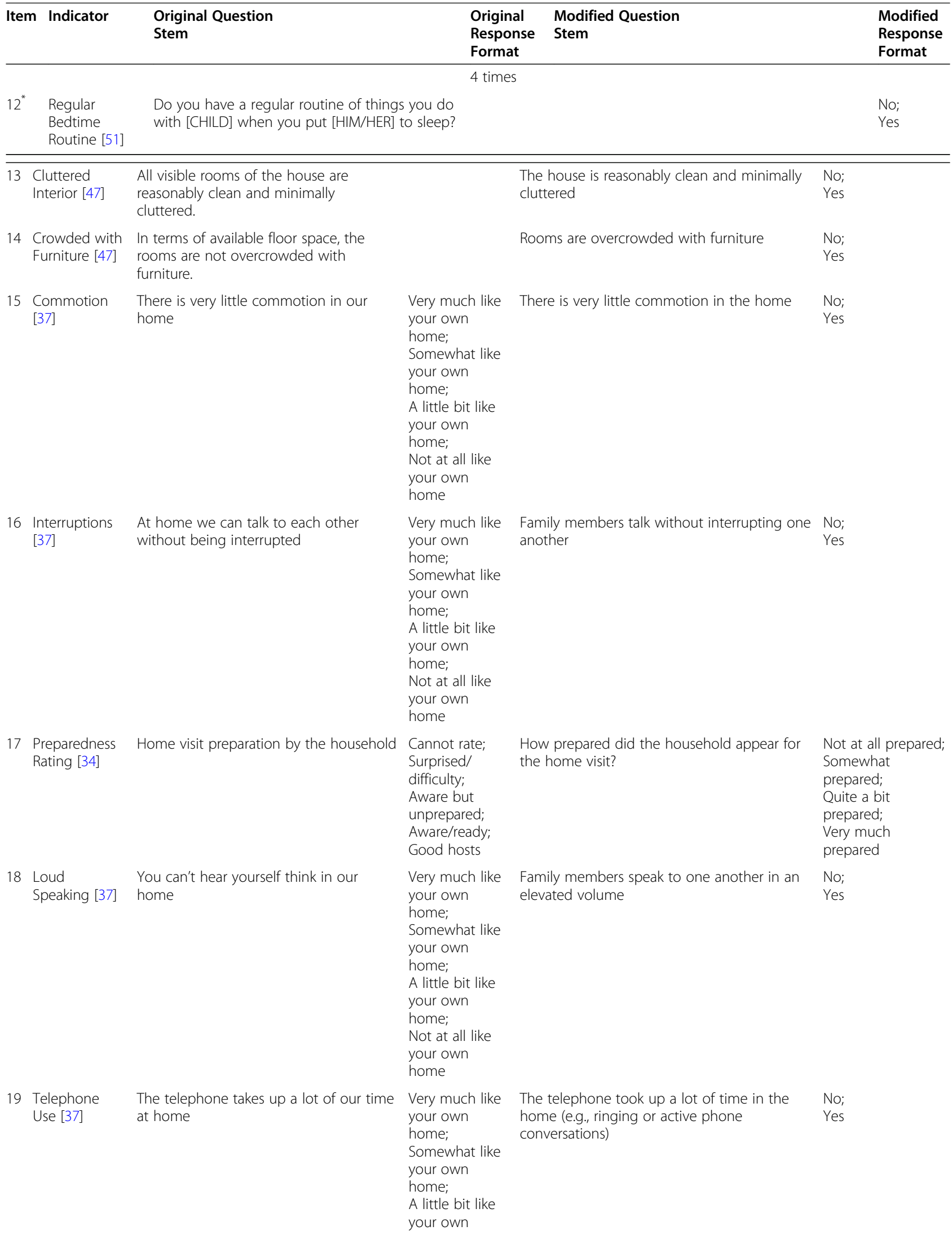


Table 2 Description of items considered as indicators of neighborhood and household chaos (Continued)

\begin{tabular}{|c|c|c|c|c|c|}
\hline & & & $\begin{array}{l}\text { home; } \\
\text { Not at all like } \\
\text { your own } \\
\text { home }\end{array}$ & & \\
\hline $20^{+}$ & $\begin{array}{l}\text { Arguments } \\
{[37]}\end{array}$ & $\begin{array}{l}\text { I often get drawn into other people's } \\
\text { arguments at home }\end{array}$ & $\begin{array}{l}\text { Very much like your } \\
\text { own home; } \\
\text { Somewhat like your } \\
\text { own home; } \\
\text { A little bit like your own } \\
\text { home; } \\
\text { Not at all like your own } \\
\text { home }\end{array}$ & $\begin{array}{l}\text { Family members are drawn into other people's } \\
\text { arguments in the home }\end{array}$ & $\begin{array}{l}\text { No; } \\
\text { Yes }\end{array}$ \\
\hline $21^{\dagger}$ & Rushed [37] & We almost always seem to be rushed & $\begin{array}{l}\text { Very much like your } \\
\text { own home; } \\
\text { Somewhat like your } \\
\text { own home; } \\
\text { A little bit like your own } \\
\text { home; } \\
\text { Not at all like your own } \\
\text { home }\end{array}$ & Family members appear rushed & $\begin{array}{l}\text { No; } \\
\text { Yes }\end{array}$ \\
\hline
\end{tabular}

"Items derived from caregiver surveys that were administered as part of the 18- and 24-month assessments

${ }^{\dagger}$ Excluded from exploratory factor analysis due to little variation in item responses

provided. Based on group consensus, definitions for ratings and descriptions were recorded and organized in a manual for reference and future trainings. During the field component, trainees traveled to the home of a research team member where each trainee completed and discussed the observation form. Trainees, who consisted mostly of college-educated, white, middle-class females under age 40 years, were required to demonstrate $80 \%$ rater agreement from a minimum of five observations before they were certified to collect data.

\section{Data analyses}

\section{Quantitative analysis}

We used items from the observation of neighborhood and home environments to describe chaos. The original data collection tool consisted of 32 items. However, some of these items were better indicators of socioeconomic disadvantage or more aligned with constructs such as neighborhood social cohesion [54] or neighborhood disorder and decay [48]. Therefore, we selected 14 items that were most like other measures of environmental and household chaos (Table 2). We also included another seven items derived from caregiver surveys that were administered as part of the 18- and 24-month visits (Table 2) to supplement measurements of household instability (often characterized by changes in parental romantic relationship status, household moves, changes in income or parental employment, and disruption to family routines) [18]. We chose to do this because such indicators are not possible to observe during a 100-min home visit. We reviewed the distributions of responses for the initial 21 items and chose to exclude two due to little variability in item responses. Thus, we sought to empirically derive measures of environmental and household chaos from a total of 19 items (Table 2).

We developed scales describing chaos using exploratory factor analyses (EFA) [55] with unweighted least squares and oblique (Promax) rotation methods. All items considered for the EFA were ordinal or binary. Therefore, our factor analysis was based on polychoric correlations, rather than Pearson's correlations [56]. We chose to employ unweighted least squares for ordinal indicators, because it has been shown to be robust to smaller sample sizes, skewed data, and provides greater accuracy and less variability in estimates, when compared to diagonally weighted least squares [57].

Factor extraction was informed by a scree plot [58] and our theoretical understanding of chaos. Our final factor structure required factors to have a minimum of three items, as fewer than three items generally results in weak factors [58]. Following previously published work, we assigned an item to a factor if the primary loading was $\geq|0.40|$ [57] and the item did not crossload (loading was $<|0.32|$ for other factors) [58]. If an item failed to meet our criteria for factor assignment, the item was removed during the structure development process. Once our factor structure was identified, we generated summary scores for our measures of chaos. Because our EFA included items with different response options (e.g., No $=1$, Yes $=2$ versus Very Quiet $=1$, Quiet $=2$, Noisy $=3$, Very Noisy $=4$ ), we chose to rescale items within a range $[0,1]$ using minmax feature scaling [59] to ensure items were equally weighted. Once rescaling was completed, we summed items according to their factor assignments then estimated the internal consistency for each scale using Cronbach's Alpha. 
We conducted descriptive statistics (means, standard deviations (SD), and $P$ values from one-way ANOVA) to described how measures of chaos distribute across characteristics of the sample, including child, caregiver, and household characteristics. Variables to describe cohort characteristics were predominantly derived from the caregiver survey administered at the 18-month assessment. Quantitative analyses, including the EFA, were conducted using SAS (version 9.4, SAS Institute, Cary, $\mathrm{NC})$.

\section{Qualitative analysis}

Due to the large number of homes visited by researchers during the 24-month assessment, we chose to examine and compare qualitative records from a randomly selected subset of families. To do this, we categorized factor scores into quartiles and randomly selected records from the highest quartile and records from the lowest quartile of factor scores. A thematic analysis [60] was conducted using the brief ethnographies. Informed by the indicators of chaos selected from the neighborhood and household observation, we used a deductive approach to develop codes, though an initial round of open coding was completed to assess patterns in the data and codes missing from our a priori coding structure [61]. A final codebook was constructed with code definitions to ensure consistency across coding. Coding was conducted by the first author and records were coded until thematic saturation [52] was achieved. A total of 88 records were coded and codes were managed electronically using QSR NVivo (Version 12, QSR International, Victoria, Australia).

\section{Results}

\section{Quantitative findings}

The scree plot showed a large break between two and three factors and a smaller break between four and five factors. The eigenvalues for the first five factors were $4.1,2.2,1.5,1.2$, and 0.9 . The total variance explained by two, three, and four factors combined were 58.2, 72.4, and $83.4 \%$, respectively. We examined the factor structures of a two, three, and four factor solutions to assess the face validity of each potential scale. Both the three and four factor solutions contained numerous indicators that cross-loaded and factors with less than three items. Therefore, we concluded a two-factor solution provided the best fit for our data.

Table 3 Factor loadings from exploratory factor analysis of environmental and household chaos indicators

\begin{tabular}{|c|c|c|c|}
\hline & & Factor 1: & Factor 2: \\
\hline Item No. & Item Name & Household Disorganization & Neighborhood Noise \\
\hline 1 & Interior Noise Rating & -0.79 & 0.16 \\
\hline 13 & Cluttered Interior & 0.51 & -0.31 \\
\hline 15 & Commotion & 0.84 & -0.04 \\
\hline 16 & Interruptions & 0.61 & -0.05 \\
\hline 17 & Preparedness Rating & 0.78 & -0.11 \\
\hline 18 & Loud Speaking & -0.61 & 0.09 \\
\hline 14 & Crowded with Furniture & -0.40 & 0.06 \\
\hline 19 & Telephone Use & -0.47 & 0.30 \\
\hline 2 & Hear Exterior Noise Inside & 0.08 & 0.75 \\
\hline 3 & Rating of Exterior Noise Audible Inside & -0.05 & 0.84 \\
\hline 5 & Exterior Noise Rating & -0.26 & 0.65 \\
\hline 4 & Loud Ambient Sounds & -0.13 & 0.45 \\
\hline \multicolumn{4}{|c|}{ Items not assigned to any factor } \\
\hline 6 & Number of Changes to Household Roster & -0.20 & 0.05 \\
\hline 7 & Regular Mealtime Routine & 0.23 & -0.02 \\
\hline 8 & Number of Adults in the Household & 0.07 & -0.03 \\
\hline 9 & Number of Children in the Household & -0.26 & -0.06 \\
\hline 10 & Caregiver Marital Status Change & -0.31 & -0.11 \\
\hline 11 & Total Residential Moves & -0.31 & 0.06 \\
\hline 12 & Regular Bedtime Routine & 0.34 & -0.06 \\
\hline
\end{tabular}

Note: $\mathrm{N}=283$; Exploratory factor analysis using unweighted least squares and Promax rotation; Inter-factor correlation was $0.13, p=0.03$; Cronbach's Alpha 0.73 and 0.67 for household disorganization and neighborhood noise, respectively; Items were not assigned to any factor if their primary factor loading was $<|0.40|$ or if they cross-loaded (had a factor loading $\geq|0.32|$ with another factor) 
Our final factor structure required factors to have a minimum of three items, factor loadings $\geq|0.40|$, and no cross-loaded items. As a result, seven items were excluded from our factor assignments (Table 3). Eight items were assigned to the first factor. We labeled this factor household disorganization and it included items describing interior household conditions and household dynamics, such as interior noise, clutter, commotion, overcrowding with furniture, telephone use, communication between household members, and overall preparedness for the study visit. Our second factor, labeled neighborhood noise, consisted of four items describing the types and amount of noise heard outside participants' homes (Table 3).

After rescaling items within a range of $[0,1]$, theoretical scores for household disorganization could range from $[0,8]$, though observed scores ranged from $[0,7.3]$ (mean $=2.1 ; \mathrm{SD}=1.8) \quad($ Table 4$)$. Theoretical and observed scores for neighborhood noise ranged from $[0,4]$ $($ mean $=1.6 ; \mathrm{SD}=1.1)$. Cronbach's Alpha was acceptable for both scales $(0.73$ and 0.67 for household disorganization and neighborhood noise respectively).

Children's gestational age and sex were not associated with measures of chaos (Table 4). As expected, higher levels of both household disorganization and neighborhood noise were associated with characteristics often indicative of socioeconomic (dis)advantage, though there was variability within these groups. Caregivers living in more disorganized homes and more noisy neighborhoods tended to be younger, identify as non-Hispanic Black or non-Hispanic other (including multiple races), were less educated, and were more often unmarried. Additionally, participants from more disorganized homes and noisy neighborhoods less often lived in single-family homes and reported lower annual household income. The number of household occupants was associated with household disorganization, but not neighborhood noise, with higher ratings of disorganization assigned to households with two occupants or five or more occupants and lower ratings assigned to households with three or four occupants. Symptoms of depression were marginally associated with household disorganization $(p=0.07)$, but not associated with neighborhood noise $(p=0.45)$. Finally, food insecurity was significantly associated with more household disorganization $(p<0.001)$, but only marginally associated with neighborhood noise $(p=$ 0.05).

\section{Qualitative findings}

\section{Household disorganization}

Qualitative data from our brief ethnographies supported the quantitative indicators that were selected to describe household disorganization (Table 5). The indicator for commotion provided a summary of the amount of movement, activities, and noise occurring within the home. Thus, other indicators, like the interior noise rating, interruptions, and loud speaking, were often intertwined with descriptions of commotion within households. In homes with higher levels of disorganization (quartile 4), researchers often noted people talking over one another or yelling. Staff also noted increased foot traffic within homes. For example, one observer wrote,

"...several people... were coming in and out of the house while we were there... a teenage boy present at the beginning of the visit...left. The... father also came home partially through the meal... people were entering and exiting from... the back of the apartment."

In contrast, homes labeled as being the least disorganized (quartile 1) were depicted as "...not having a lot of activity going on." Observers used words like "calm", "peaceful", and "relaxing" to describe to overall atmosphere for such homes and family members were often described as speaking at low, even volumes (some staff used the phrase "indoor voices"). Qualitative descriptions of telephone use also varied. Namely, in households that were the most disorganized, observers more frequently described noise from telephones or use of mobile phones during visit activities, whereas in the most organized homes, staff noted rarely seeing or hearing mobile phones.

Descriptions of clutter inside homes were often interwoven with descriptions of crowding due to furniture. Together, these indicators appeared to illustrate the organization of a home's physical space. For example, in homes that were the most disorganized, staff illustrated environments where tables and other surfaces were covered in various items, like household ornaments, papers, laundry, or appliances. During one home visit, a household member shared her experience of "losing her stuff in the home due to how cluttered it [was]". Staff also described environments that were so crowded with furniture and other items that the space appeared to be "unusable" or "difficult to get around". In contrast, homes described as having the least disorganization appeared to have organizational systems in the form of "bins" or "shelves" that helped "consolidate" household items, like children's toys. Additionally, furniture did not appear to interfere with mobility throughout the home.

The rating for family preparedness often reflected signs that participants remembered their scheduled visit and attempted to follow visit-preparation instructions provided by the research team. In homes with high levels of disorganization, observers frequently noted that 
Table 4 The distribution of household disorganization and neighborhood noise according to cohort characteristics

\begin{tabular}{|c|c|c|c|c|c|c|}
\hline & \multicolumn{3}{|c|}{ Household Disorganization } & \multicolumn{3}{|c|}{ Neighborhood Noise } \\
\hline & \multicolumn{3}{|c|}{ (Range: $0-7.3$ ) } & \multicolumn{3}{|c|}{ (Range: $0-4$ ) } \\
\hline & Mean & SD & $P$ Value & Mean & SD & $P$ Value \\
\hline Overall & 2.1 & (1.8) & - & 1.6 & (1.1) & - \\
\hline
\end{tabular}

Gestational Age at Birth

37-41 Completed Weeks (term)

0.14

(1.1)

0.43

< 37 Completed Weeks (preterm)

Sex

Boy

Primary Respondent Characteristics

Age (years) at enrollment

18 to $<21$

25 to $<30$

30 to $<35$

35 to $<40$

40 or older

Race/Ethnicity

Non-Hispanic white

Non-Hispanic Black

(1.6)

$<0.001$

Non-Hispanic other (includes multiple races)

Educational Attainment

High school diploma/GED or less

$$
<0.001
$$

Some college

Bachelor's degree

Post-graduate degree

Marital Status

Single/Never Married

Living with Partner

Other

Endorsed Symptoms of Depression

$\begin{array}{ll}\text { No } & 2.0 \\ \text { Yes } & 2.7\end{array}$

$(1.8)$
$(1.7)$

0.07

\section{Household Characteristics}

Housing Type

\begin{tabular}{|c|c|c|c|c|c|c|}
\hline Single Family Home & 1.7 & $(1.6)$ & $<0.001$ & 1.4 & $(1.1)$ & $<0.001$ \\
\hline Other & 2.8 & $(1.8)$ & & 1.9 & $(1.0)$ & \\
\hline \multicolumn{7}{|c|}{ Number of Household Members } \\
\hline 2 members & 2.7 & (1.9) & $<0.001$ & 1.2 & $(0.8)$ & 0.26 \\
\hline 3 members & 1.5 & $(1.5)$ & & 1.7 & $(1.0)$ & \\
\hline 4 members & 1.8 & $(1.5)$ & & 1.5 & $(1.1)$ & \\
\hline
\end{tabular}


Table 4 The distribution of household disorganization and neighborhood noise according to cohort characteristics (Continued)

\begin{tabular}{|c|c|c|c|c|c|c|}
\hline 5 or more members & 2.8 & (1.9) & & 1.5 & $(1.1)$ & \\
\hline \multicolumn{7}{|l|}{ Food Insecurity } \\
\hline Food Secure & 1.9 & $(1.7)$ & $<0.001$ & 1.5 & (1.1) & 0.05 \\
\hline Food Insecure & 2.8 & $(1.7)$ & & 1.9 & $(1.1)$ & \\
\hline \multicolumn{7}{|l|}{ Annual Household Income } \\
\hline$<\$ 20$ thousand & 3.0 & $(1.8)$ & $<0.001$ & 2.0 & $(1.1)$ & $<0.001$ \\
\hline$\$ 20$ to $<\$ 50$ thousand & 2.5 & (1.9) & & 1.6 & $(1.0)$ & \\
\hline$\$ 50$ to $<\$ 90$ thousand & 1.4 & $(1.1)$ & & 1.2 & $(1.0)$ & \\
\hline$\$ 90$ thousand or more & 1.1 & (1.3) & & 1.4 & $(1.1)$ & \\
\hline
\end{tabular}

Note: Participant characteristics were predominately derived from caregivers surveys collected at the 18-month (enrollment) assessment for Play \& Grow. Descriptions of household disorganization and neighborhood noise were derived from direct observations conducted in family homes when children were approximately 24-months of age. Higher scores of household disorganization and neighborhood noise are indicative of higher levels of chaos; SD = standard deviation; $P$ values were calculated using one-way ANOVA; Food insecurity was assessed using the U.S. Department of Agriculture Food and Nutrition Service's guidelines for measuring food security. We coded families as having food insecurity if they indicated experiencing any level food insecurity in the 12-months prior to them completing our surveys. Depression symptomology was determined using the Center for Epidemiological Studies Depression Survey, with a score $\geq 16$ indicated symptoms of depression

caregivers did not complete surveys ahead of time and did not place pets in a separate space before allowing staff to enter their home. Additionally, other family members sometimes appeared "surprised" by the presence of staff, suggesting participants did not inform them of the visit. Conversely, staff were often greeted promptly by caregivers from homes with the least disorganization. Family members could sometimes be seen waiting at the door or looking through windows in anticipation of study staff arrival. Caregivers often complete surveys within the recommended timeframe and placed family pets in separate rooms or outside prior to staff entering the home. There was also evidence from the least chaotic homes of family communication in preparation for the visit. For example, one observer wrote, "...It was evident that mom and dad had discussed the study... before we got there... [because] there was no question about who would do what activities...".

In addition to themes directly supporting our quantitative measure of household disorganization, we also noted excerpts describing aspects of the social environment that extended past our eight indicators. For example, in the least disorganized homes, observers consistently noted exchanges and interactions between household members that were generally peaceful and harmonious. In such cases, both caregivers and children appeared to be "very engaged" and enjoyed their time together. One observer wrote,

"[The child] was engag[ed] and seem[ed] really happy to be with mom. Mom... always responded to him, was chatting with him, and smiling at him. [The child] often looked to mom for feedback... Even when mom was busy with the survey, she was always paying attention to [the child] enough to [respond] to him when he [addressed] her."
Peaceful exchanges noted by staff often occurred during home visits where more than one caregiver was present (in most cases the child's mom and dad). Caregivers were described as behaving "warm[ly]" and "friendly" towards one another and were often successful at "divide... tasks between each other". Caregivers' ability to remain "calm and patient" with their children, even during tantrums or moments of fussiness, appeared to result in more peaceful interactions overall.

Staff also noted displays of affection or support between family members living in more organized households. Such descriptions often included moments when researchers observed a caregiver and child hugging or cuddling. Caregivers shared with study staff positive feelings they had towards their children. For example, one father "... spoke about [his children's] school and about the [child participant's] growth in vocabulary and mentioned that he had counted to eight." In other instances, staff noted other family members, like siblings, demonstrating support for the participating child,

\section{"[older sister] wanted to help [her brother] when he was upset during measurements by showing him how to do them [and] that they were easy and not at all scary. She even held his hand during height measurements...".}

In contrast, homes with higher levels of disorganization often included staff descriptions of more turbulent exchanges between household members. In such cases, caregivers and children were often observed struggling through visit activities.

"Mom... seemed very stressed when child did not understand [or] did not follow her requests... [She] 
Table 5 Example excerpts providing preliminary construct validity of indicators of chaos selected from the exploratory factor analysis

\section{Quantitative Levels of Chaos Indicators \\ High Disorganization \\ (15) With the limited space, siblings going up and down stairs, parents Commotion going up and down stairs and elevated voices, it felt very chaotic in the home. \\ (1) Interior ...there were six other siblings that were in the home two of Noise Rating which were very young and stayed in the kitchen with staff, they all spoke in their normal speaking voices, but with the small space it echoed loudly in the home and seemed louder... The smoke detector beeped during the entire visit indicating the battery needed to be changed and the washer was running during... activities.}

(16) A few minutes into the visit, multiple siblings and friends walked Interruptions through the back door. They loudly spoke over one another, and it was difficult to hear [the] mom and [child] over them. Throughout the visit, mom would yell across the house at siblings to get them to do various tasks or to come join for the meal.

(18) Loud The great grandma got upset with the dogs [for barking] and Speaking yelled at them several times saying "I'm going to bust you!"

(19) Mom's phone made a lot of noise... Mom spent most of our visit Telephone looking at her phone and playing with the youngest baby.

Use

(13) Cluttered ..The seven-year-old [cousin]... described losing her stuff in the Interior; home due to how cluttered it is. She [said she] carried her toys and clothes around in a trash bag to keep track of them.

\section{Low Disorganization}

The home was calm and peaceful...Both parents... did not appear to be in any rush..... The] home [did] not have a lot of activity going on.

The home was mostly quiet. The child whined..., [but] was not overly loud. Dad and sister played and read together. [They] giggled and spoke but were mostly quiet/[indoor] speaking volume. I could not hear any sounds from household appliances.

While family spoke often, their voices were never raised. I would describe it as using "indoor voices".

They never raised their voices to the children but were stern [at times]...

I never heard or saw mom or dad use their phone during the visit.

Playroom had lots of interactive toys: cars with racetrack that could shoot off the cars into a loop-de-loop, play kitchen set, animated toys that sing/dance, blocks/building things. Toys were scattered around the edges of the room, or in smaller baskets, so it seemed like the space had an organization system.

(14) Crowded When we walked into the home, there was a living room with a with Furniture couch, big chair, two desk chairs, highchair, coffee table, tv stand, and TV. In addition to the furniture, there was a guitar, big speakers, random pieces of wood, unidentified electronic devices, and lots of wires. This room was hard to navigate, and I had trouble finding a spot to do anthropometric measurements. I also felt like I kept accidentally bumping into furniture or knick-knacks on the furniture.

(17) Survey was done hours before the visit... [When we arrived] Preparedness grandma answered the door and seemed surprised we were Rating there. [She] spent at least 3 min wrangling the dogs to get them out of the way while we waited outside.

\section{High Neighborhood Noise}

(5) Exterior The apartment complex... was in was on the corner of a fairly

Noise Rating busy cross section. About 20 cars passed by in front of the home and about the same amount passed by on the other direction to the side of the building... We heard a emergency vehicle siren and honking, most likely more than one for about 3 mins or more... Occasionally heard a low rumbling of a large engine in the distance. Around the same time as the sirens, we heard a small engine airplane and then a helicopter nearby. When all was quiet, there was a faint whoosh from the traffic in the distance.
The living room had a couple very large couches and a round leather ottoman and coffee table, but it was not overcrowded and there was a lot of open space.... Against the back wall were many plastic bins with kids toys organized in them, and some toys out on the floor.

Dad greeted us at the door promptly after we knocked. The dog was locked away upstairs before we even entered... Dad showed signs of remembering details of the study and seemed prepared for what we were doing at the home visit... Mom was running a few minutes late, but she wasn't the primary respondent and dad had already communicated that she was be home a few minutes after we arrived prior to us showing up for the home visit. All signs indicated the family was well-prepared for our visit.

\section{Low Neighborhood Noise}

The neighborhood was very quiet. I could not hear any highway traffic, only the occasional car driving past where we were parked or a nearby street. Traffic volume was light. I only counted 4-5 cars passing by during the observation. I did not note any noise from airplanes or trains. Neighbors from across the street were walking out to their car and yelling. One person yelled, "Oh my God! Unlock the door".
(4) Loud Ambient In the 15 mins we sat there, 3 airplanes went by producing a Sounds

(2) Hear Exterior Noise Inside

very loud sound and lasting for at least a min each time.

When sitting in the living room you can hear the cars/trucks passing by from the street. Also hear people's voices outside, one airplane sound, and music (possibly coming from a different apartment but also may be outside). [l rated it] as very noisy because of the multiple sounds. ...the sounds of a very high altitude plane flying overhead--it was so faint that I wouldn't consider it "loud ambient" noise.

I was not able to hear any noise coming from outside, even when we were hanging around the front door to hide out of site during the meal 
Table 5 Example excerpts providing preliminary construct validity of indicators of chaos selected from the exploratory factor analysis (Continued)

\begin{tabular}{ll}
\hline (3) Rating of & ...the sound from the road traffic outside was very noticeable I was only able to hear some of the traffic from outside when \\
Exterior Noise & inside the home. The adult's bedroom shared the wall that faced \\
Audible Inside & $\begin{array}{l}\text { the street, and so did the main living space. Child's room was } \\
\text { towards the back of the house. I could hear regular passenger } \\
\text { vehicles, but especially large semi's as they drove past. }\end{array}$
\end{tabular}

kept apologizing throughout the visit... [and] would make... comments [to her son] like, "Come on, you can do this. I know you can do this for us. Why aren't you?"...”

In fewer cases, staff witnessed family members engaging in active arguments during the study visit. For example, one researcher observed, "Mom and partner [having] another hushed, but agitated argument when they thought we were out of ear shot. Mom used several expletives." Finally, researchers often used words like "passive" or "lack of engagement" to describe caregivers in households that were more disorganized.

\section{Neighborhood noise}

Qualitative data from our brief ethnographies provided preliminary construct validity for our indicators of neighborhood noise (Table 5). In most neighborhoods, the exterior noise rating represented a holistic description of the types of noise and the volume of such noises observed over a brief period. Across levels of neighborhood noise, staff indicated car traffic, in the neighborhood or on a nearby thoroughfare, was a consistent source of noise. However, among a subset of neighborhoods with the highest noise ratings, observers highlighted the home's proximity to major highways/interstates. One staff member wrote,

"The apartment complex was built directly next to the highway. There was only a concrete partition separating the highway from the complex parking lot. The partition did very little to cut down noise. It sounded like I should be able to see the vehicles as they drove past, but I couldn't. The highway noise was extremely loud and constant. I could identify every semi-truck that went by."

Conversely, in the quietest neighborhoods, observers would sometimes draw attention to the distance between the participant's home and known interstate highways (e.g., "the neighborhood is a little more secluded from the interstate and main road"). In such cases, staff sometimes noted a participant's home was in "a [more] rural part of the city", on a cul-de-sac, or had a "dense forest of trees blocking..." sounds from nearby highways.
Ambient noises were often the same across neighborhoods, despite the level of noise observed. Airplanes and emergency vehicle sirens were frequently heard. Occasionally, staff would note the presences of noise from a nearby construction site or an individual vehicle with a loud engine. However, among homes described as having the lowest neighborhood noise, researchers more frequently described sources of ambient noise as being noticeable to a lesser degree. They did this by conditioning their descriptions using words like "faint" or "muffled", or described noise as being "sporadic" rather than "constant". Unique to neighborhoods with the highest noise ratings, some observers noted the presence of loud music playing from vehicles driving through the neighborhood. One researcher wrote, "two cars pulled in at different times that had their music turned up very loud... we could feel [vibrations from] the bass".

The ability to hear neighborhood noises from inside participant homes differed according to neighborhood noise ratings. In homes from the quietest neighborhoods, research staff often made statements like, "no outside noises [could be] heard from inside the home". Sometimes staff would suggest that interior sounds, such as subtle humming from appliances or family members talking, might "drown... out" the exterior noises. In the few cases where neighborhood noises could be heard while inside the home, observers made a point to note that the family had the "... windows [and] front door... open because of the weather" or that study staff "...were hanging around the front door..." when they heard such noises. In contrast, while inside homes located in the noisiest neighborhoods, observers repeatedly described hearing vehicle or highway noise and loud ambient noises, such as sirens, airplanes, and at times, construction. For example, one observer wrote, "We could also hear noise from the highway and construction outside, especially the large trucks going by." Another offered, "[I] could hear some loud engines revving outside and then an airplane and train at one point." In fewer cases, research staff also noted being able to hear loud music playing from passing vehicles while inside the home. For instance, "...there were several... cars [with loud stereos] that pulled into the complex that we could hear the beat and the tune of the song they were listening to [from] inside the home". On the rare occasion that observers were unable to hear neighborhood noises while 
inside a participant's home, staff suggested the inability to hear such noises may be due to characteristics of the home. For example, one researcher wrote, "I tried very hard to hear highway noise and couldn't. Either the building materials did a good job insulating against noise pollution, or the [air conditioning] was... loud enough... to cover the exterior noise, or both."

\section{Discussion}

\section{Summary of findings}

Chaos is known to negatively influence a wide range of family, caregiver, and child outcomes [19]. In recent years, researchers have considered the role of chaos in child weight status, but results are mixed, and conclusions are limited by the heterogeneity in which chaos is operationalized $[15,33,62]$. To improve upon limitations of previous chaos-obesity investigations, we proposed reconceptualizing aspects of chaos to facilitate future research efforts that aim to determine which (if any) matter for childhood obesity development. Thus, in the present study we examined the underlying structure of multiple indicators of family-level chaos from direct observations of neighborhood and home environments, using a concurrent mixed methods approach. We found evidence to suggest numerous indicators of chaos may be governed by higher-order constructs, including household disorganization and neighborhood noise. This evidence was further supported by themes derived from qualitative fieldnotes, which provide preliminary construct validity for a novel chaos assessment tool.

The methodology and results in the present study closely align with those described by Vernon-Feagans and colleagues (2012), who assessed family-level chaos via direct observations using multiple indicators of chaos [34]. Concurrent with their methods and results, we utilized direct observations of family homes and found evidence to suggest chaos may be comprised of multiple constructs. However, our study incorporated both quantitative and qualitative assessment of chaos, which presented opportunities for data triangulation, expansion of descriptions of chaos, and further contextualized the broader social and material environments in which chaos occurred [52]. For example, in addition to providing evidence to support our indicators of chaos, themes emerged from our qualitative analysis to suggest family dynamics varied according to the level of household disorganization. Specifically, among homes with the lowest levels of disorganization, study staff described what appeared to be more peaceful and harmonious exchanges between household members. In contrast, observers noted a greater frequency of turbulent exchanges between household members from homes with the highest levels of disorganization. Previous research suggests greater family functioning [63] and high quality relationships between caregivers and children [64-66] may be protective against childhood obesity. Yet, chaos may degrade the quality of such relationships [24, 67]. It has also been proposed that the quality of interpersonal interactions occurring between family members may moderate the effect of chaos on children's risk for obesity. For example, one qualitative study conducted semistructured interviews with 20 ethnically diverse caregiver-child dyads (children aged 9-15 years) and described experiences where household chaos not only influenced the structure and quality of family meals, but also created more challenging mealtime interactions among family members experiencing difficulties in their interpersonal relationships [68]. Similar findings were echoed from one quantitative study among 108 caregiver-toddler dyads where researchers reported children exposed to higher levels of chaos engaged in obesogenic eating behaviors to a greater degree, but only when maternal emotional responsiveness during mealtimes was low [69]. The pathways by which chaos may be linked to child weight outcomes are likely complex, and the unique challenges associated with caring for young children may add to family-level chaos, creating additional stress for caregivers. Our qualitative findings build upon emerging literature which suggests caregiverchild interactions may be important context for studies of chaos-obesity relationships, especially during early developmental periods, like toddlerhood. However, given the exploratory nature of these findings, this interpretation is speculative and requires additional study to determine how chaos and caregiver-toddler interaction may work in concert to influence childhood obesity risk.

Our scale describing disorganization closely aligns with what Matheny and colleagues labeled environmental confusion, in the development of the CHAOS [37]. This suggests the CHAOS may provide a foundation for developing measurement tools designed for structured, direct observations of disorganization in family homes. We believe direct observations may be necessary to avoid potential bias often associated with caregiverreported measures [70]. For example, one study examining parent and adolescent perceptions of household chaos using the CHAOS $(N=261$ parent-adolescent dyads) found perceptions of chaos in shared home environments were only moderately correlated $(r=0.32)$, implying individual differences may influence perceptions of chaos [71]. Another analysis examined associations between maternal personality characteristics and perceptions of chaos using the CHAOS $(N=94)$ and concluded mothers with high stimulus sensitivity perceived home environments as more chaotic than what was objectively measured by trained observers [38]. While caregiverreported measures offer quick, cost-effective alternatives to direct observations, disentangling caregiver 
characteristics from measures of chaos may be impossible without more objective assessments. Still, direct observations conducted by trained researchers are not without shortcomings, including vulnerability to bias resulting from observers' personality, knowledge, beliefs, and experiences. We were mindful of this limitation when designing our data collection procedures. To mitigate potential bias in our direct observations, staff were trained to collect both descriptive and reflecting fieldnotes which facilitated staff engagement in reflexivity as they assigned ratings. Never-the-less, individual biases may have played a role in our observations. Therefore, concurrent use of caregiver-reported and objective measures of chaos in future studies may be an essential next step to inform future chaos-related research.

A second factor of chaos, neighborhood noise, was identified through our EFA. Studies examining noise, as one feature of chaos, suggest cardiovascular stress indicators and neuroendocrine stress hormones, implicated in obesity development, may be sensitive to louder environments [72]. However, current definitions of chaos include little specificity around types and sources of noise $[17,37]$. Interestingly, one indicator of chaos from our observation, that described the level of interior noise, was highly correlated with our factor of disorganization, but minimally correlated with our factor of neighborhood noise. Such distinctions may suggest noise typologies are a necessary level of nuance for measuring environmental and household chaos, with different implications for childhood obesity research. For example, our thematic analysis further contextualized our neighborhood noise ratings by indicating that participants living in the noisiest neighborhoods often lived close to interstate highways. Highway construction in the U.S. has disproportionately burdened Black and Brown communities and contributed to the residential concentration of poverty [73]. Obesity is known to be a condition that disproportionately affects non-white children [74, 75] and children residing in households with fewer socioeconomic resources [76]. Thus, neighborhood noise may be one aspect of chaos more closely linked with structural disadvantage and requires multifaceted interventions designed to address a variety of upstream social inequalities. Future studies of chaos, within the context of child weight development, may benefit from efforts to describe the variability of chaos within and across socioeconomic groups.

Contrary to what we hypothesized, our EFA did not identify instability as an independent factor contributing to chaos. Prior to selecting our final model, we considered other factor structures that incorporated indicators thought to be associated with instability, such as mealtime routines, bedtime routines, and changes to the household composition. However, the internal consistencies associated with these alternative structures were poor, the face validity was less convincing, and we found little to no support for alternative structures in our qualitative data. Moreover, our lack of support for instability as a factor of chaos may be attributed to the cross-sectional nature of our study design. For example, Vernon-Feagans and colleagues (2012) identified instability as an independent factor of chaos through direct observations of family homes. However, VernonFeagans et al. (2012) conducted repeated assessments over a three year period [34]. Unlike other aspects of chaos, which tend to persist, instability often occurs periodically. Thus, single assessments of chaos may be insufficient for detecting factors, like instability. Within this vein, time may be a key component missing in most studies examining associations between chaos and earlychildhood weight outcomes. For example, null findings have been reported in cross-sectional studies examining direct associations between caregiver-reported chaos and early-childhood weight outcomes [13, 14]. Conversely, one study that assessed caregiver-reported chaos twice over a six month period indicated infant BMI z-score was significantly higher when household chaos (the average from the two assessments) was higher [15]. Therefore, longitudinal assessments may be necessary for identifying molar constructs thought to govern chaos, as well as associations that may exist between chaos and early-childhood weight outcomes.

\section{Limitations}

Our study has limitations that must be considered. Observations of chaos were conducted during a single visit in participant homes. As some aspects of chaos may be acute while others are chronic, we may not have observed the true variation of environmental and household chaos. Furthermore, the presence of study staff and execution of study protocols during the visit may have contributed to an unusual home environment that factored into our staff's ratings. Future studies incorporating objective measure of chaos should strive for repeated assessments to ensure what is measured is "typical" for households. Our data collection tool for measuring household chaos was novel. Thus, without more rigorous testing of psychometric properties, construct validity and generalizability of our tool may be limited. Furthermore, protocols for conducting observations were developed and implemented by mostly middle-class, white females and our initial training for our observation protocol was limited to a single field practice component in a neighborhood where one research team member resided. While few studies have examined challenges to conducting direct observations of chaos, a wealth of research demonstrates divergent descriptions of parenting styles when researchers seek to observe behaviors across 
diverse groups [77, 78]. Though our protocols and trainings attempted to overcome systematic error using multiple methodologies, our homogenous research team did not reflect the diverse cohort of families making up the Play \& Grow study. Therefore, it is possible that researcher observations reflect cultural differences that may or may not be symbolic of chaos. Furthermore, most observers interacted and built rapport with families at previous assessments. It is unknown whether these previous interactions influence ratings and fieldnotes. Finally, though we included two items on household routines in our quantitative assessment, household routines were largely neglected from our observations of chaos. Family routines may be key aspects of chaos with important implications for childhood obesity [32, 79]. Future research should combine factors, such as disorganization and noise, with measure of family routines to understand how best to operationalize chaos.

\section{Conclusions}

Chaos represents a complex, multifaceted construct with implications spanning various research disciplines [80], including public health research focused on early childhood obesity. Previous research investigating chaosobesity relationships in early-childhood may be limited by the challenges associated with measuring chaos. Therefore, this study advanced the literature by contributing to efforts to reconceptualize aspects of chaos and identifying conceptually distinct subdomains, including disorganization and neighborhood noise. As obesity prevention researchers look to family home environments as preferred settings for prevention efforts [81], more contemporary measures, such as those relying on direct observations which account for multiple underlying factors of chaos, may yield valuable insight on factors contributing to early-childhood obesity risk.

\section{Abbreviations \\ CHAOS: The Confusion, Hubbub, and Order Scale; NCH: Nationwide Children's Hospital; RAP: Rapid Assessment Procedures; EFA: Exploratory Factor Analysis}

\section{Acknowledgements}

We are grateful for the participation of the families and the contributions of the research staff without whom this project would not have been possible. The authors would like to extend special thanks to Amanda James, Antonio Malloy-McCoy, Chase Beeman, Grace Pelak, Jackie Sullivan, Megan Puritz, and Melissa Kravets for their assistance with data collection.

\section{Authors' contributions}

KLK designed and conceptualized this research, led data collection, led analyses and interpretation of data, and wrote the manuscript. AP participated in the design and conceptualization of data collection methods, assisted with data collection, assisted with analyses, and critically revised the manuscript. RA advised the conceptualization of analytic methods, supervised data analyses, and critically reviewed the manuscript. BZ participated in early development of the data collection methods and critically reviewed the manuscript. SAK supervised data collection and critically reviewed the manuscript. SEA supervised the design and conceptualization of this research, supervised analyses, and interpretation of data, and critically revised the manuscript. The author(s) read and approved the final manuscript.

\section{Funding}

This work was supported by the National Institute of Diabetes and Digestive and Kidney Diseases of the National Institutes of Health under award number R01DK108969 and supported by the National Center for Advancing Translational Research of the National Institutes of Health under award number CTSA Grant UL1TR002733. The content is solely the responsibility of the authors and does not necessarily represent the official views of the National Institutes of Health.

\section{Availability of data and materials}

The datasets used and/or analyzed during the current study are available from the corresponding author on reasonable request.

\section{Declarations}

Ethics approval and consent to participate

The study was conducted in accordance with the Declaration of Helsinki and approved by the Institutional Review Board at Nationwide Children's Hospital (IRB16-00826). Participants provided written informed consent.

\section{Consent for publication}

Not Applicable.

\section{Competing interests}

The authors declare that they have no competing interests.

\section{Author details}

${ }^{1}$ Division of Epidemiology, College of Public Health, The Ohio State University, 336 Cunz Hall, 1841 Neil Ave, Columbus, OH 43210, USA. ${ }^{2}$ Center for Biobehavioral Health, Abigail Wexner Research Institute at Nationwide Children's Hospital, 700 Children's Dr. NEOB 3rd Floor, Columbus, OH 43205, USA. ${ }^{3}$ Division of Biostatistics, College of Public Health, The Ohio State University, 1841 Neil Ave, Columbus, OH 43210, USA. ${ }^{4}$ Department of Maternal and Child Health, Gillings School of Public Health, University of North Carolina at Chapel Hill, 135 Dauer Dr., Chapel Hill, North Carolina 27599, USA. ${ }^{5}$ Department of Pediatrics, College of Medicine, The Ohio State University, 370 W. 9th Ave, Columbus, OH 43210, USA.

Received: 10 February 2021 Accepted: 5 October 2021

Published online: 16 October 2021

\section{References}

1. United Nations Children's Fund (UNICEF), World Health Organization, International Bank for Reconstruction and Development/World Bank. Levels and trends in child malnutrition: key findings of the 2019 edition of the Joint Child Malnutrition Estimates. Geneva, Switzerland: World Health Organization; 2019. https://apps.who.int/iris/bitstream/handle/10665/331 097/WHO-NMH-NHD-19.20-eng.pdf?ua=1

2. Simmonds M, Llewellyn A, Owen CG, Woolacott N. Predicting adult obesity from childhood obesity: a systematic review and meta-analysis. Obes Rev. 2016;17(2):95-107 https://doi.org/10.1111/obr.12334.

3. Craigie AM, Lake AA, Kelly SA, Adamson AJ, Mathers JC. Tracking of obesityrelated behaviours from childhood to adulthood: a systematic review. Maturitas. 2011;70(3):266-84 https://doi.org/10.1016/j.maturitas.2011.08.005.

4. Davison KK, Birch LL. Childhood overweight: a contextual model and recommendations for future research. Obes Rev. 2001;2(3):159-71 https:// doi.org/10.1046/j.1467-789x.2001.00036.x.

5. Economos CD, Haire-Joshu D. Preventing obesity in 2-5-year olds: a pathway to advancing intervention research. Child Obes. 2020;16(S2):S2-59S52-61. https://doi.org/10.1089/chi.2020.29008.ce-S2-61.

6. Bahia L, Schaan CW, Sparrenberger K, Abreu GA, Barufaldi LA, Coutinho W, et al. Overview of meta-analysis on prevention and treatment of childhood obesity. J Pediatr. 2019;95(4):385-400 https://doi.org/10.1016/j.jped.2018.07. 009.

7. Brown T, Moore THM, Hooper L, Gao Y, Zayegh A, ljaz S, et al. Interventions for preventing obesity in children. Cochrane Database Syst Rev. 2019;7(7): CD001871. https://doi.org/10.1002/14651858.CD001871.pub4. 
8. Loprinzi PD, Trost SG. Parental influences on physical activity behavior in preschool children. Prev Med. 2010;50(3):129-33 https://doi.org/10.1016/j. ypmed.2009.11.010.

9. Pearson N, Biddle SJ, Gorely T. Family correlates of fruit and vegetable consumption in children and adolescents: a systematic review. Public Health Nutr. 2009;12(2):267-83 https://doi.org/10.1017/S1368980008002589.

10. Davis MM, Gance-Cleveland B, Hassink S, Johnson R, Paradis G, Resnicow K. Recommendations for prevention of childhood obesity. Pediatrics. 2007; 120(Supplement 4):S229-53 https://doi.org/10.1542/peds.2007-2329E.

11. Davison KK, Jurkowski JM, Lawson HA. Reframing family-centred obesity prevention using the family ecological model. Public Health Nutr. 2013; 16(10):1861-9 https://doi.org/10.1017/S1368980012004533.

12. Fiese $B H$, Rhodes $H G$, Beardslee WR. Rapid changes in American family life: consequences for child health and pediatric practice. Pediatrics. 2013:peds. 2013-0349. https://doi.org/10.1542/peds.2013-0349.

13. Boles RE, Halbower AC, Daniels S, Gunnarsdottir T, Whitesell N, Johnson SL. Family chaos and child functioning in relation to sleep problems among children at risk for obesity. Behav Sleep Med. 2017;15(2):114-28 https://doi. org/10.1080/15402002.2015.1104687.

14. Lumeng JC, Miller A, Peterson KE, Kaciroti N, Sturza J, Rosenblum K, et al. Diurnal cortisol pattern, eating behaviors and overweight in low-income preschool-aged children. Appetite. 2014;73:65-72 https://doi.org/10.1016/j.a ppet.2013.10.016.

15. Khatiwada A, Shoaibi A, Neelon B, Emond JA, Benjamin-Neelon SE. Household chaos during infancy and infant weight status at 12 months. Pediatric Obesity. 2018;13(10):607-13 https://doi.org/10.1111/ijpo.12395.

16. Appelhans BM, Fitzpatrick SL, Li H, Cail V, Waring ME, Schneider KL, et al. The home environment and childhood obesity in low-income households: indirect effects via sleep duration and screen time. BMC Public Health. 2014; 14(1):1160. https://doi.org/10.1186/1471-2458-14-1160.

17. Wachs TD, Evans GW. Chaos in context. In: Evans GW, Wachs TD, editors. Chaos and its influence on Children's development: an ecological perspective. Second ed. Washington, DC: American Psychological Association; 2010. https://doi.org/10.1037/12057-001.

18. Forman EM, Davies PT. Family instability and young adolescent maladjustment: the mediating effects of parenting quality and adolescent appraisals of family security. Journal of Clinical Child and Adolescent Psychology. 2003;32(1):94-105 https://doi.org/10.1207/S153 74424JCCP3201_09.

19. Marsh S, Dobson R, Maddison R. The relationship between household chaos and child, parent, and family outcomes: a systematic scoping review. BMC Public Health. 2020;20(1):1-27. https://doi.org/10.1186/s12889-020-08587-8.

20. Brody GH, Flor DL. Maternal psychological functioning, family processes, and child adjustment in rural, single-parent, African American families. Developmental Psychology. 1997;33(6):1000. https://doi.org/10.1037/0012-1 649.33.6.1000-11.

21. Evans GW, Gonnella C, Marcynyszyn LA, Gentile L, Salpekar N. The role of Chaos in poverty and Children's Socioemotional adjustment. Psychol Sci. 2005;16(7):560-5 https://doi.org/10.1111/j.0956-7976.2005.01575.x

22. Garrett-Peters PT, Mokrova I, Vernon-Feagans L, Willoughby M, Pan Y. family life project key I. the role of household chaos in understanding relations between early poverty and children's academic achievement. Early Child Res Q. 2016;37:16-25 https://doi.org/10.1016/j.ecresq.2016.02.004.

23. Wachs TD. Viewing microsystem Chaos through a Bronfenbrenner bioecological Lens. In: Evans GW, Wachs TD, editors. Chaos and its influence on Children's development, vol. 1. Washington, DC: American Psychological Association; 2000.

24. Evans GW, Hart B, Maxwell LE. Parental language and verbal responsiveness to children in crowded homes. Dev Psychol. 1999;35(4):1020-3 https://doi. org/10.1037//0012-1649.35.4.1020.

25. Zvara BJ, Mills-Koonce WR, Garrett-Peters P, Wagner NJ, Vernon-Feagans L, Cox $\mathrm{M}$, et al. The mediating role of parenting in the associations between household chaos and children's representations of family dysfunction. Attach Hum Dev. 2014;16(6):633-55 https://doi.org/10.1080/14616734.2014 966124

26. Schore AN. Attachment, affect regulation, and the developing right brain: linking developmental neuroscience to pediatrics. Pediatr Rev. 2005;26(6): 204-17 https://doi.org/10.1542/pir.26-6-204.

27. McEwen BS. Understanding the potency of stressful early life experiences on brain and body function. Metabolism. 2008;57:S11-5 https://doi.org/10.1 016/j.metabol.2008.07.006.
28. Peters A, Kubera B, Hubold C, Langemann D. The selfish brain: stress and eating behavior. Front Neurosci. 2011;5:74 https://doi.org/10.3389/fnins.2011. 00074.

29. Liew J, Zhou Z, Perez M, Yoon M, Kim M. Parental child-feeding in the context of child temperament and appetitive traits: evidence for a biopsychosocial process model of appetite self-regulation and weight status. Nutrients. 2020;12(11):3353 https://doi.org/10.3390/nu12113353.

30. Llewellyn C, Wardle J. Behavioral susceptibility to obesity: Geneenvironment interplay in the development of weight. Physiology \& Behavior: Part B. 2015;152(Part B):494-501 https://doi.org/10.1016/j. physbeh.2015.07.006.

31. Dovey TM, Staples PA, Gibson EL, Halford JC. Food neophobia and 'picky/ fussy'eating in children: a review. Appetite. 2008;50(2-3):181-93 https://doi. org/10.1016/j.appet.2007.09.009.

32. Anderson SE, Whitaker RC. Household routines and obesity in US preschoolaged children. Pediatrics. 2010:peds. 2009-0417. https://doi.org/10.1542/ peds.2009-0417.

33. Bates CR, Buscemi J, Nicholson LM, Cory M, Jagpal A, Bohnert AM. Links between the organization of the family home environment and child obesity: a systematic review. Obes Rev. 2018;19(5):716-27 https://doi.org/1 $0.1111 /$ obr.12662

34. Vernon-Feagans L, Garrett-Peters P, Willoughby M, Mills-Koonce R. Chaos, poverty, and parenting: predictors of early language development. Early Child Res Q. 2012;27(3):339-51 https://doi.org/10.1016/j.ecresq.2011.11.001.

35. Schuch I, Castro TG, de Vasconcelos FA, Dutra CL, Goldani MZ. Excess weight in preschoolers: prevalence and associated factors. J Pediatr. 2013; 89(2):179-88 https://doi.org/10.1016/j.jped.2013.03.003.

36. Jones BL, Fiese BH. Parent routines, child routines, and family demographics associated with obesity in parents and preschool-aged children. Front Psychol. 2014;5:374 https://doi.org/10.3389/fpsyg.2014.00374.

37. Matheny AP Jr, Wachs TD, Ludwig JL, Phillips K. Bringing order out of chaos: psychometric characteristics of the confusion, hubbub, and order scale. J Appl Dev Psychol. 1995;16(3):429-44 https://doi.org/10.1016/0193-3973 (95)90028-4.

38. Wachs TD. Relation of maternal personality to perceptions of environmental chaos in the home. J Environ Psychol. 2013;34:1-9 https://doi.org/10.1016/j. jenvp.2012.11.003.

39. The Family Life Project. About FLP. https://flp.fpg.unc.edu/about-flp.

40. Parrott AM, Zvara BJ, Keim SA, Andridge R, Anderson SE. Design of the Play \& Grow cohort: a prospective study of parent-child mealtime interactions. medRxiv. 2020;Manuscript submitted for publication. https://doi.org/10.11 01/2020.06.11.20128637

41. Annett H, Rifkin SB, World Health Organization. Guidelines for rapid participatory appraisals to assess community health needs: a focus on health improvements for low-income urban and rural areas 1995(WHO/SHS/ DHS/95.8. Unpublished). https://apps.who.int/iris/handle/10665/59366.

42. Ackerman S, Gleason N, Gonzales R. Using rapid ethnography to support the design and implementation of health information technologies. Studies in Health Technology and Informatics. 2015;215:14-27 https://doi.org/1 0.3233/978-1-61499-560-9-14

43. Scrimshaw SC, Carballo M, Ramos L, Blair BA. The AIDS rapid anthropological assessment procedures: a tool for health education planning and evaluation. Health Educ Q. 1991;18(1):111-23. https://doi.org/1 0.1177\%2F109019819101800111. https://doi.org/10.1177/109019819101 800111.

44. Moloney K, Scheuer H, Engstrom A, Schreiber M, Whiteside L, Nehra D, et al. Experiences and insights from the early US COVID-19 epicenter: a rapid assessment procedure informed clinical ethnography case series. Psychiatry. 2020;83(2):1-13. https://doi.org/10.1080/00332747.2020.1750214.

45. Ackerman SL, Sarkar U, Tieu L, Handley MA, Schillinger D, Hahn K, et al. Meaningful use in the safety net: a rapid ethnography of patient portal implementation at five community health centers in California. J Am Med Inform Assoc. 2017;24(5):903-12 https://doi.org/10.1093/jamia/ocx015.

46. Brownson RC, Hoehner CM, Brennan LK, Cook RA, Elliott MB, McMullen KM. Reliability of 2 instruments for auditing the environment for physical activity. J Phys Act Health. 2004;1(3):191-208 https://doi.org/10.1123/jpa h.1.3.191.

47. Bradley RH, Caldwell BM, Rock SL, Hamrick HM, Harris P. Home observation for measurement of the environment: development of a home inventory for use with families having children 6 to 10 years old. Contemp Educ Psychol. 1988;13(1):58-71 https://doi.org/10.1016/0361-476X(88)90006-9. 
48. Ross CE, Mirowsky J. Disorder and decay: the concept and measurement of perceived neighborhood disorder. Urban Aff Rev. 1999;34(3):412-32. https:// doi.org/10.1177\%2F107808749903400304. https://doi.org/10.1177/1 0780879922184004.

49. Andresen EM, Malmstrom TK, Schootman M, Wolinsky FD, Miller JP, Miller DK. Observer ratings of neighborhoods: comparison of two methods. BMC Public Health. 2013;13(1):1-12 https://doi.org/10.1186/1471-2458-13-1024.

50. Berlin KS, Davies WH, Silverman AH, Rudolph CD. Assessing family-based feeding strategies, strengths, and mealtime structure with the feeding strategies questionnaire. J Pediatr Psychol. 2011;36(5):586-95 https://doi. org/10.1093/jpepsy/jsp107.

51. The Early Childhood Longitudinal Study-Birth Cohort. ECLS-B national 2-year parent questionnaire: section HE--home environment. https://nces.ed.gov/ ecls/pdf/birth/parent24.pdf Accessed May 27, 2021.

52. Hess-Biber SN. The practice of qualitative research: engaging students in the research process. Third ed. Thousand Oaks, CA: SAGE Publications Ltd; 2017.

53. Emerson RM, Fretz RI. Shaw LL. Writing ethnographic fieldnotes: University of Chicago Press; 2011. https://doi.org/10.7208/chicago/9780226206868.001.0001.

54. McNeill LH, Kreuter MW, Subramanian S. Social environment and physical activity: a review of concepts and evidence. Soc Sci Med. 2006;63(4):101122 https://doi.org/10.1016/j.socscimed.2006.03.012.

55. DeVellis R. Scale development theory and applications, vol. 26. Second ed. Thousand Oaks, CA: Sage Publications, Inc.; 2003.

56. Holgado-Tello F, Moscoso S, Barbero-García I, Vila E. Polychoric versus Pearson correlations in exploratory and confirmatory factor analysis with ordinal variables. Qual Quant. 2010;44(1):153-66. https://doi.org/10.1007/ s11135-008-9190-y.

57. Forero CG, Maydeu-Olivares A, Gallardo-Pujol D. Factor analysis with ordinal indicators: a Monte Carlo study comparing DWLS and ULS estimation. Struct Equ Model. 2009;16(4):625-41 https://doi.org/10.1080/10705510903203573.

58. Costello AB, Osborne J. Best practices in exploratory factor analysis: four recommendations for getting the most from your analysis. Practical Assessment, Research, and Evaluation. 2005;10(1):-7 https://doi.org/10.7275/ jyj1-4868.

59. Pei J, Kamber M, Han J. Data mining: concepts and techniques. Netherlands: Elsevier Science; 2011.

60. Saldana J. The coding manual for qualitative researchers. First ed. Thousand Oaks, CA: SAGE Publications Ltd; 2009.

61. Braun V, Clarke V. Using thematic analysis in psychology. Qual Res Psychol. 2006;3(2):77-101 https://doi.org/10.1191/1478088706qp063oa.

62. Riley HO, Lo SL, Rosenblum K, Sturza J, Kaciroti N, Lumeng JC, et al. Sex differences in the association between household chaos and body mass index z-score in low-income toddlers. Child Obes. 2020;16(4):265-73 https:// doi.org/10.1089/chi.2019.0186.

63. Berge JM, Wall M, Larson N, Loth KA, Neumark-Sztainer D. Family functioning: associations with weight status, eating behaviors, and physical activity in adolescents. J Adolesc Health. 2013;52(3):351-7 https://doi.org/1 0.1016/j.jadohealth.2012.07.006

64. Anderson SE, Gooze RA, Lemeshow S, Whitaker RC. Quality of early maternal-child relationship and risk of adolescent obesity. Pediatrics. 2012; 129(1):132-40 https://doi.org/10.1542/peds.2011-0972.

65. Anderson SE, Keim SA. Parent-child interaction, self-regulation, and obesity prevention in early childhood. Curr Obes Rep. 2016;5(2):192-200 https://doi. org/10.1007/s13679-016-0208-9.

66. Anderson SE, Whitaker RC. Attachment security and obesity in US preschool-aged children. Archives of Pediatrics \& Adolescent Medicine. 2011;165(3):235-42 https://doi.org/10.1001/archpediatrics.2010.292.

67. Coldwell J, Pike A, Dunn J. Household chaos-links with parenting and child behaviour. J Child Psychol Psychiatry. 2006;47(11):1116-22 https://doi.org/1 0.1111/j.1469-7610.2006.01655.x.

68. Rosemond TN, Blake CE, Shapiro CJ, Burke MP, Bernal J, Adams EJ, et al. Disrupted relationships, Chaos, and altered family meals in food-insecure households: experiences of caregivers and children. J Acad Nutr Diet. 2019; 119(10):1644-52 https://doi.org/10.1016/j.jand.2019.05.005.

69. Saltzman JA, Bost KK, McBride BA, Fiese BH. Household chaos, maternal emotional responsiveness, and child eating behavior: a moderation analysis. J Dev Behav Pediatr. 2019;40(8):622. https://doi.org/10.1097/DBP. 0000000000000701-32.

70. Holden GW, Edwards LA. Parental attitudes toward child rearing: instruments, issues, and implications. Psychol Bull. 1989;106(1):29. https://doi. org/10.1037/0033-2909.106.1.29-58.
71. Human L, Dirks MA, DeLongis A, Chen E. Congruence and incongruence in adolescents' and parents' perceptions of the family: using response surface analysis to examine links with adolescents' psychological adjustment. Journal of Youth and Adolescence. 2016;45(10):2022-35 https://doi.org/10.1 007/s10964-016-0517-z.

72. Ferguson KT, Cassells RC, MacAllister JW, Evans GW. The physical environment and child development: an international review. Int J Psychol. 2013;48(4):437-68 https://doi.org/10.1080/00207594.2013.804190.

73. Archer DN. "white men's roads through black men's homes": advancing racial equity through highway reconstruction. 2020. https://perma.cc/6YCRPKKR

74. Hales CM, Carroll MD, Fryar CD, Ogden CL. Prevalence of obesity among adults and youth: United States, 2015-2016. Centers for Disease Control and Prevention: Hyattsville, MD; 2017. https://stacks.cdc.gov/view/cdc/49223

75. Hales CM, Fryar CD, Carroll MD, Freedman DS, Ogden CL. Trends in obesity and severe obesity prevalence in US youth and adults by sex and age, 2007-2008 to 2015-2016. JAMA. 2018;319(16):1723-5 https://doi.org/10.1001/ jama.2018.3060

76. Ogden C, Lamb M, Carroll M, Flegal K. Obesity and socioeconomic status in children: United States 1988-1994 and 2005-2008. National Center for Health Statistics: Hyattsville, MD; 2010. https://www.cdc.gov/nchs/data/data briefs/db51.pdf

77. Power TG, Sleddens EF, Berge J, et al. Contemporary research on parenting: conceptual, methodological, and translational issues. Childhood Obesity. 2013;9(s1):S-87-94 https://doi.org/10.1089/chi.2013.0038.

78. Gonzales NA, Cauce AM, Mason CA. Interobserver agreement in the assessment of parental behavior and parent-adolescent conflict: African American mothers, daughters, and independent observers. Child Dev. 1996 67(4):1483-98 https://doi.org/10.1111/j.1467-8624.1996.tb01809.x.

79. Anderson SE, Sacker A, Whitaker RC, Kelly Y. Self-regulation and household routines at age three and obesity at age eleven: longitudinal analysis of the UK millennium cohort study. Int J Obes. 2017;41(10):1459-66 https://doi. org/10.1038/ijo.2017.94.

80. Emond JA. Household chaos: a risk factor for adverse child outcomes gains attention in public health. BMC Public Health. 2020;20(1):1-4 https://doi. org/10.1186/s12889-020-08680-y.

81. O'Kane C, Wallace A, Wilson L, et al. Family-based obesity prevention: perceptions of Canadian parents of preschool-age children. Can J Diet Pract Res. 2017;79(1):13-7. https://doi.org/0.3148/cjdpr-2017-027. https://doi.org/1 0.3148/cjdpr-2017-027.

\section{Publisher's Note}

Springer Nature remains neutral with regard to jurisdictional claims in published maps and institutional affiliations.

Ready to submit your research? Choose BMC and benefit from:

- fast, convenient online submission

- thorough peer review by experienced researchers in your field

- rapid publication on acceptance

- support for research data, including large and complex data types

- gold Open Access which fosters wider collaboration and increased citations

- maximum visibility for your research: over $100 \mathrm{M}$ website views per year

At $\mathrm{BMC}$, research is always in progress.

Learn more biomedcentral.com/submission 